\title{
Sleep problems in internationally adopted children: a pilot study
}

This article was published in the following Dove Press journal:

Nature and Science of Sleep

\author{
Eva Schenkels' \\ Nicky Steinfort ${ }^{1}$ \\ Marek Wojciechowski' \\ Stijn Verhulst ${ }^{1,2}$ \\ 'Department of Pediatrics, Antwerp \\ University Hospital, Edegem, Belgium; \\ ${ }^{2}$ Lab of Experimental Medicine and \\ Pediatrics, University of Antwerp, \\ Antwerp, Belgium
}

\section{Dear editor}

Approximately $25 \%$ of children experience a sleep problem. ${ }^{1}$ Medical conditions and social and emotional stress can impact developing sleep patterns. Internationally adopted children could therefore be at risk. Although many adoptive parents report a sleep problem in their children, ${ }^{2-5}$ these studies have not focused on sleep specifically or used validated sleep questionnaires. To the best of our knowledge, two studies in adopted children used validated sleep questionnaires. However, the first study only investigated sleep in maltreated children with behavioral difficulties, ${ }^{6}$ and the second study mainly investigated the role of marital distress on the development of sleep disorders in children unrelated to genetic factors. ${ }^{2}$ Therefore, this study aimed to investigate sleep disorders in internationally adopted children.

This study was approved by the Ethics Committee of the Antwerp University Hospital, and all participants provided written informed consent. Parents of adopted children (under 12 years) were approached through several adoption agencies and the "Institute of Tropical Medicine." All adopted children arrived in Belgium $<6$ months ago. Parents of the control group were approached through well-child clinics and day care centers. All completed the Pediatric Sleep Questionnaire, Brouillette obstructive sleep apnea (OSA) Score, International Study of Asthma and Allergies in Childhood (ISAAC) Questionnaire, Restless Legs Syndrome Questionnaire, Epworth Sleepiness Scale, and a sleep diary for one week.

Twenty seven adopted children ( 16 boys), average age of 2.9 years, were included in the adoption group (response rate of $23 \%$ ). Ninety-three children (52 boys) with an average age of 3.3 years made up the nonadoption group. Both groups were comparable for age, gender, parents' level of education, and family composition. The age of the parents was higher in the adoption group. Overall, adopted children showed a significantly higher prevalence of any disorder of initiating and/or maintaining sleep (DIMS) (67\% vs $40 \% ; P=0.01)$, defined as a sleep latency of more than 30 minutes on average or more than one hour on $\geq 1$ night during the week, restless sleep, and frequent nocturnal awakenings. About $44 \%$ of the adopted children were categorized as having possible restless legs syndrome (RLS), defined as having a frequent urge to move the legs, compared to $12 \%$ of children in the control group $(P<0.001)$. No significant differences were found for parasomnia, nocturnal enuresis, or snoring.
Correspondence: Stijn Verhulst Department of Pediatrics, Antwerp University Hospital, Wilrijkstraat 10, 2650 Edegem, Belgium Tel +32 282 I 325I

Email stijn.verhulst@uza.be 
In logistic regression, adoption was related to DIMS (odds ratio $=3.46 ; P=0.02$ ), controlling for age (odds ratio $=0.53$; $P<0.001)$ and asthma $(P=0.3)$.

Adoption is a major life-changing event demanding a lot of adjustment and exerting a possible amount of stress. Our study found that adoption was an independent risk factor for DIMS adjusting for possible confounders. Not surprisingly, younger children also had a higher risk of DIMS. Another significant finding was a higher prevalence of "possible RLS." RLS can be very difficult for parents to evaluate. Lower ferritin levels could be an explanation for this higher prevalence, although this was not assessed in our study. The main limitations of this pilot study are the fact that no information was collected on maltreatment preceding adoption and the low response rate in both groups, possibly leading to a selection bias where parents from a child with a sleep disorder could be more likely to participate. This could also be the case for the control group where a high prevalence of DISM was noted as well. Nevertheless, both groups were comparable, and the higher prevalence of DISM and possible RLS support a future prospective study investigating the influence of adoption on sleep in children.

\section{Author contribution}

SV and MW designed the study; ES, NS, MW, and SV collected and analyzed data; ES, NS, and SV wrote the manu- script. All authors read and approved the final manuscript. All authors contributed toward data analysis, drafting and critically revising the paper and agree to be accountable for all aspects of the work.

\section{Disclosure}

The authors report no conflicts of interest in this communication.

\section{References}

1. Owens J. Classification and epidemiology of childhood sleep disorders. Prim Care. 2008;35(3):533-546.

2. Mannering AM, Harold GT, Leve LD, et al. Longitudinal associations between marital instability and child sleep problems across infancy and toddlerhood in adoptive families. Child Dev. 2011;82(4): $1252-1266$.

3. Miller LC. Immediate behavioral and developmental considerations for internationally adopted children transitioning to families. Pediatr Clin North Am. 2005;52(5):1311-1330.

4. Rettig MA, Mccarthy-Rettig K. A survey of the health, sleep, and development of children adopted from China. Health Soc Work. 2006;31(3):201-207.

5. Radcliff Z, Baylor A, Rybarczyk B. Adopted youth and sleep difficulties. Pediatric Health Med Ther. 2016;7:165-175.

6. Cuddihy C, Dorris L, Minnis H, Kocovska E. Sleep disturbance in adopted children with a history of maltreatment. Adopt Foster. 2013;37(4):404-411
Nature and Science of Sleep

\section{Publish your work in this journal}

Nature and Science of Sleep is an international, peer-reviewed, open access journal covering all aspects of sleep science and sleep medicine, including the neurophysiology and functions of sleep, the genetics of sleep, sleep and society, biological rhythms, dreaming, sleep disorders and therapy, and strategies to optimize healthy sleep. The manuscript

\section{Dovepress}

management system is completely online and includes a very quick and fair peer-review system, which is all easy to use. Visit http://www. dovepress.com/testimonials.php to read real quotes from published authors. 